\title{
Is the Post-Turing ICT Sustainable?
}

\author{
Norberto Patrignani ${ }^{1}$ and Iordanis Kavathatzopoulos ${ }^{2}$ \\ ${ }^{1}$ Politecnico of Torino, Italy and Uppsala University, Sweden \\ norberto.patrignani@polito.it \\ ${ }^{2}$ Uppsala University, Sweden \\ iordanis@it.uu.se
}

\begin{abstract}
In this paper we introduce a definition of post-Turing ICT with an initial analysis of its sustainability. At the beginning of the history of computing the attention was concentrated on the single machine: a device able to read and write a memory and able to execute different actions depending on the internal state. It was only in the 1960's that the fifth function (after input, memory, processing and output) was introduced: the network, the capability of this single computational node to be connected and exchange data with similar machines. In the last fifty years the network has grown at an incredible speed, introducing us into the post-Turing ICT era: billions of electronic devices interconnected. ICT has now a significant environmental impact along all its lifetime phases: manufacturing (based on scarce minerals), application (based on growing power consumption) and e-waste management (with open cycles difficult to close). In this paper, we introduce relevant topics to understand whether the current ICT production and consumption paradigms are sustainable, and the social consequences and implications of such a problem for stakeholders.
\end{abstract}

Keywords: post-Turing, sustainability, material intensity, cloud computing, open hardware, smart software applications, e-waste management, stakeholders' network, social issues.

\section{Introduction}

When Alan Turing introduced the concept of a universal machine in 1937 in his historical article on "computable numbers," probably he never imagined the impact that such a machine would have had to our society. Indeed at those times the attention was concentrated on just one computational node: a machine able to read and write into a memory and to execute different actions depending on the symbols read and on the internal state [22].

In modern world we would say that the Turing Machine was able to perform the four basic functions of a computer: input, memory, processing and output. The fifth function, the capability to communicate with other computational nodes (networking) was introduced in 1969, with the "ancestor" of Internet, ARPANET, a vision of a global network: "... a network of such computers, connected to one another by wideband communication lines" [13]. 
This was the beginning of what we call the post-Turing ICT (Information and Communication Technology) era. It is based on a network of interconnected nodes, where the convergence of social networks (people interconnected, Web 2.0) and semantic web (knowledge interconnected, Web 3.0) will introduce humanity into a radically new ICT environment.

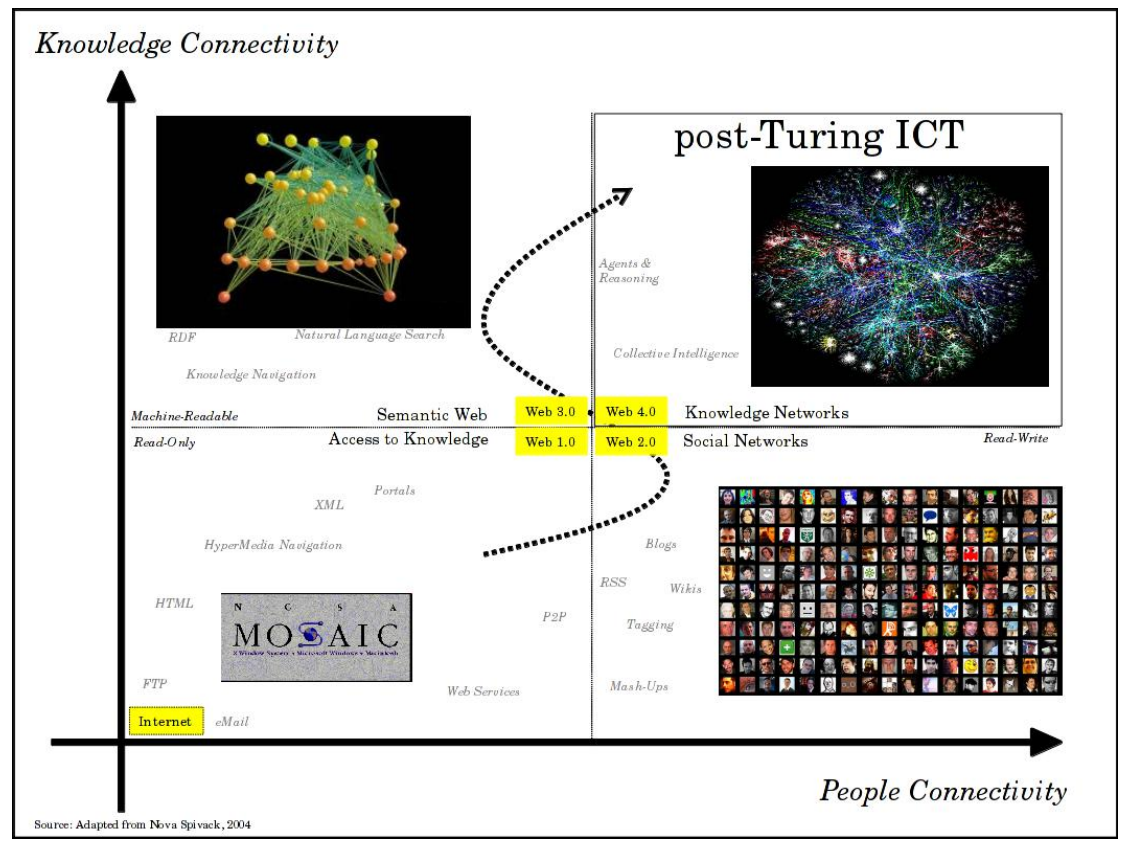

Fig. 1. Post-Turing ICT

Open and collaborative networks will take advantage of the huge amount of machine-readable knowledge, the linked open data. The last update of the Linked Open Data Project contains more than three billions of RDF (Resource Description Format) triples (subject, predicate and object) available on the Web [25].

In this new scenario it is no more the original computational node the core of our attention, but the network effect triggered by the immense power that social networks will have when they will access the global semantic web. It will empower humanity for facing many of the social and environmental challenges ahead of us: a collective intelligence using many knowledge networks. For the first time in our history, we will be able to access tools and knowledge that will enable us to face scientific challenges and to provide services like: e-accessibility for all, socio-cultural-geographical inclusion, e-ageing.

On the other side, the post-Turing ICT poses to us new questions related to its environmental, personal and social sustainability. 


\section{Environmental and Social Issues of Post-Turing ICT}

In the last forty years we have witnessed the explosion of the global network: on January 2012 we had more than 888 Million of hosts, the entries in the DNS, the Domain Name System that enable us to use symbolic names on the Internet and the Web [7]. In 2011 , the Internet traffic reached more than 500 Exabytes $\left(10^{18}\right.$ bytes $)$ and the forecast is that it will reach 1 Zetta-byte $\left(10^{21}\right.$ bytes $)$ per year in 2015 [4].

Even more impressive is that the number of Internet users reached 2.26 Billion on December 2011 with more than one billion concentrated in Asia [6]. Also, in 2011, the number of networked devices has equalled the world population (7 Billion) and it is estimated to reach more that 14 Billion in 2015 [4].

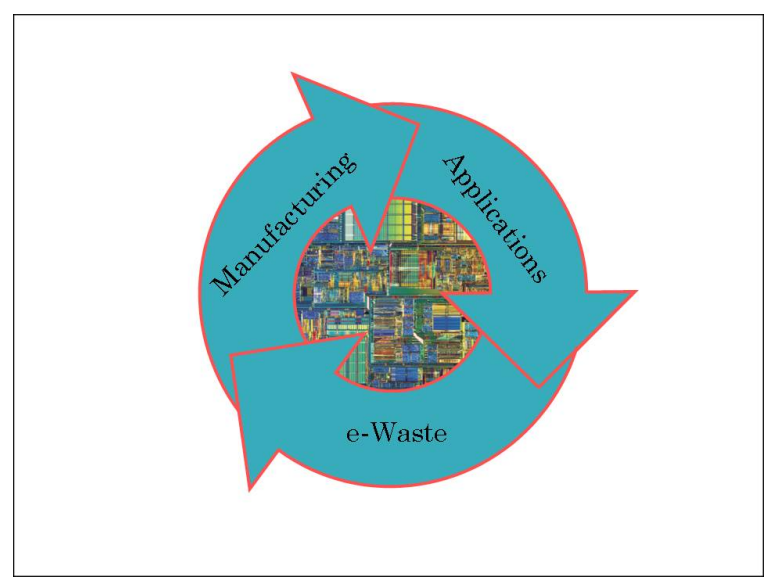

Fig. 2. The ICT life cycle

These billions of networked devices pose enormous questions along their life cycle: where does the material needed for their manufacturing come from? How will we produce the power needed to feed them when in use? How will the growing mountain of electronic waste (e-waste) be managed? How can we design usable and reliable ICTs? In what way should we use ICTs to sustain our interests as human beings?

\subsection{Manufacturing ICT}

The industrial process for producing microprocessors and chips has one of the highest "material intensities" in the industry [21] and also has an impact on the health of workers [17]. On the other side the dynamic of the so called "Moore's law" is exponential: every eighteen months the chips are more powerful [14] but at the same time they consume a growing quantity of "rare earths" [19]. Nowadays this is starting also to have serious social and political consequences. One example is the "coltan" used for producing many of the electronic devices, from laptops to smart-phones and tablets. Its name comes from the combination of names of two minerals: Columbite and 
Tantalite. From them are extracted two elements: Columbium (now called Niobium, $\mathrm{Nb}$ ) and Tantalum (Ta), fundamental for producing capacitors in the electronic industry. But these special minerals are coming from countries like Congo, where the mining activity is performed in illegal conditions for workers and have also a decisive role in the military conflicts in the area [24].

We need to start an ethical reflection about the sustainability of pursuing this direction, probably it is time to slow-down the speed of electronic market cycles and to restate the well-known Soesterberg principle about sustainability: "Each new generation of technical improvements in electronic products should include parallel and proportional improvements in environmental, health and safety, as well as social justice attributes" [20].

\subsection{Using ICT}

Of course, when we power on ICT devices and infrastructure, we process information, and this could have also a positive contribution to the environment, for example by reducing the air pollution with tele-working and by organizing car-sharing. Probably we need to better use ICT in this direction: "Further research is needed to understand how ICTs and the Internet can contribute to reaching environmental policy goals by fostering renewable energy, reducing transport, optimising energy use and reducing material use" [15]. On the other side, we see that the power consumption of these machines is growing at the incredible rate of about $100 \%$ every five years [11]. The new ICT paradigm based on cloud computing is also under scrutiny, due to the computing power and storage capability concentrated in gigantic data centres located in remote locations: "under some circumstances cloud computing can consume more energy than conventional computing where each user performs all computing on their own personal computer $(P C)$ " [2].

In conclusion, we realize that ICT requires more and more energy and many researches now estimate that its contribution to greenhouse gases (such as $\mathrm{CO} 2$ ) is close to that of airlines.

\subsection{Managing e-Waste}

It is estimated that, in 2020, Europe will produce more than 12 million tons of e-waste and that the mountain of this electronic waste is growing at $4 \%$ per year [8]. Only a small percentage of these devices are recycled in some way and if we have a look at its destinations we will see many poor countries like: Haiti, Kenya, and Nigeria [21]. We now recognize also the importance of introducing new design principles like design-for-recycle and minimizing the power consumption of ICT. Also a promising sign is the new field of "open hardware", where thousands of experts exchange ideas and innovative proposals for improving hardware.

\subsection{Social Issues of Post-Turing ICT}

The post-Turing ICT scenario poses also new questions about social issues, as discussed in the following paragraphs. 
Accessibility and Digital Divide. In the post-Turing ICT scenario, having the network accessibility, the economic conditions and the digital competence for being online is becoming more and more a "new human right": Finland, for example, has become the first country in the world to make broadband a legal right for every citizen; since July 2010 every Finnish will have the right to access to a $1 \mathrm{Mbps}$ broadband connection. Finland has vowed to connect everyone to a $100 \mathrm{Mbps}$ connection by 2015 [3]. So the "digital divide" will risk excluding more seriously those who are still disconnected.

Network Neutrality. The connectivity providers (mainly telecommunication companies) are questioning the business model based on "network neutrality," which is that the Internet works end-to-end and the network is acting as a "pipeline" that is "neutral" in that it does not open the data-packets. This "network neutrality" principle that is at the base of the Internet is also the great enabler of innovations: many start-ups and new companies were able to experiment new services because of this characteristic of the network. But the telcos are willing to introduce new business models where the network will be no more neutral, and the data-packets will not be treated at the same level.

This will risk introducing a kind of first-class and second-class services based on the price you are willing to pay. This could also mine the great opportunity of the post-Turing scenario, since small and innovative companies will have to leave network bandwidth to big companies.

Knowledge as a Commons. The new currency in the post-Turing era will be information (and knowledge). For this reason around knowledge is open a hot debate regarding its openness as "commons" or if it should be regarded as any other good subject to restrictions of use and distribution.

This debate is very open now but the main researches around innovation are now demonstrating that intellectual property legislations, born centuries ago, are no more fitting with the new knowledge-based society [12]. Even the 2009 Nobel Prize in Economic Sciences, Elinor Ostrom, underlined the growing importance of understanding knowledge as a shared social-ecological system [16].

The application of this framework is now moving from free and open source software, to open hardware and to scientific knowledge.

Internet Censorship and Control. The knowledge networks of the post-Turing era are, by definition, free and open. At the same time this new scenario, where information and knowledge are becoming strong liberation tools in many cultures, there are a growing number of governments around the world that are trying to stop this "freedom wave."

For example the 2011 Report from Reporters Without Borders, highlighted the fact that "the Internet and social networks have been conclusively established as tools for protest, campaigning and circulating information, and as vehicles for freedom" but that at the same time "repressive regimes responded with tougher measures to what 
they regarded as unacceptable attempts to 'destabilize' their authority" [18]. They can also use the information accessible on the Internet to persecute dissidents.

Indeed this new scenario is outside any previous communication schema: it is without a "single point of control" and it is based on a global collaboration between networks based on open standards. It is difficult to control, even if few new titans are emerging and collecting the vast amount of search engines traffic and data about everything, included ourselves [23]. Strong players have always more resources to spread certain information in sophisticated ways in order to manipulate people they target.

Remote Working. The impact of computers into the workplace have been investigated since the 1960's but now, for understanding what does it mean to work in global knowledge networks, we need a leap into a new scenario. In particular for knowledge workers, working in a "virtual workplace for a virtual enterprise" is becoming a daily experience.

The XXI century's enterprise is (symmetrically) becoming, a "workplace without workers." We have more and more knowledge workers hired "on demand" by global job brokers: brains stay in their (poor) countries, but minds cross the oceans. As a consequence, the "social" context of the traditional workers is completely disappearing.

Now we have global job broker agencies like: teamlease.com from India that is providing well-educated workers all over the world; odesk.com that provides all kind of contractors; getacoder.com that helps in finding freelance programmers; and, elance.com that "helps businesses hire and manage in the cloud." Young programmers hired on-demand and with a good knowledge of English can make up to $\$ 300$ per month [10], [5]. These deep social issues in this post-Turing era restate very old questions: are we going towards a utopian participation of (knowledge) workers in the new enterprises or are we going towards a dystopian new kind of cyber-slavery?

Privacy. Probably privacy is the oldest social and ethical issue related to computing. What is new in our global knowledge networks scenario? From one side the inclusion of our physical body into the network via RFID tags is turning our bodies into nodes at the edge of the network. From the other side we have the gigantic amount of collected data (so called Big Data) that will enable very few powerful organizations to analyse and extract new information through special data mining technologies.

They will be able also to find "non-obvious relationships" (also known as the "mosaic" effect) by collecting information about us from different sources. A good example of this advanced use of data mining and Big Data is the "Narwhal Project," a project that could change the results of the 2012 U.S. President elections [9].

Cloud Computing. The vast amount of computing and storage resources available in big data centres, convinced large corporations to start making them available to customers. They can provide on-demand and in a flexible way: software as a service (SaaS), where users can just use sophisticated software applications by paying a fee for each user; platform as a service (PaaS), where users can have access to large processing power and development environments for testing their applications; and 
infrastructure as a service (IaaS), where users can buy storage and processing capability readily available in the cloud provider's data centre.

This big shift in computing paradigms will enable decision makers to move ICT from capex (capital expenditure, money spent to acquire physical assets, machinery) to opex (operating expense, ongoing cost for running a system). At the same time, this development is opening a long list of issues: strong authentication will become a requirement, using a resource will be completely separated from ownership, cloud brokers will be new intermediaries that complicate the picture, we will have a kind of $d e-$ perimeterization (disappearing of boundaries between systems and organizations), it will be possible to clone data at a negligible cost, cloud traceability will be necessary in case of disasters, the risk of monopoly and lock-in will increase, and the actual data location must be disclosed for some legal compliance requirements.

Also, information could be downloaded not (necessarily) only by the up-loader, creating an issue of intellectual property: sensitive personal and corporate information risk to be out of the control of the owners.

Internet Governance. The global infrastructure is open and without a center, nevertheless there are few "core" systems that have become very critical for the entire infrastructure, such as the Domain Name System.

The very critical collection of systems and applications that allow the use of symbolic names over the Internet and the Web has to be unique by definition. This uniqueness introduces one of the few "central" resources of the network: the need for an authority that will release unique names and will take care of the management of this gigantic "table."

This authority is now the famous ICANN (Internet Corporation for Assigned Names and Numbers), based in the U.S. This authority is one of the many controversies that have been discussed for several years in the Internet Governance Forum, the last of which was in Nairobi in 2011.

In these yearly forums, several global issues related to the global Internet governance are addressed: security, accessibility, critical infrastructures, and many others. The post-Turing ICT scenario poses huge questions to international bodies like the UN and the ITU (International Telecommunication Union) but it is difficult to find global agreements related to a commons like the Internet.

Information Overload. Once we are globally interconnected and "always on," we recognize also that our minds have a limited bandwidth and have limits in "absorbing" messages. We need time for thinking and questioning, we cannot simply stay always online and receiving millions of inputs. Somewhere we need to stop those inputs and have a little of silence. We need this for avoiding "information overload" and also for building our autonomy, our interpreting codes, and our histories. Otherwise the risk is that we will be totally manipulated. Slowing down the pace of incoming messages will become a strategic resource in a post-Turing scenario.

A New World. A post-Turing scenario implies the creation of a new social world. Its novelty and its difference are of course important aspects but the way it comes to the 
fore is also significant because it is out of our control. The state of interconnections, communications and collaborations emerges by itself and by chance depending on previous or prevalent conditions at a certain time and place. What is there has not been explicitly designed for any particular reason by anybody. Thus the questions are: Is it sustainable in itself? And where does it lead us?

\section{Concluding Discussion}

Taking into the account the issues above, what are the implications for society? What are the key aspects we need to change in our paradigms? How could we do that?

The post-Turing scenario will introduce humanity into an interconnected world with global knowledge networks, with the promising "collective intelligence" opportunity. But at the same time, this poses to humanity a collection of sustainability issues on the environmental, personal, biological and social sides.

On the environmental side we will need to slow down the consumption of natural resources for building electronic devices and improve the re-use and re-cycling of hardware. We need to start thinking ourselves as (responsible) "digital citizens" and not just "digital consumers." We need to question the market pressure of consuming new electronic gadgets at a growing speed. Also, in order to have really recyclable hardware, we need to introduce recyclable-by-design devices. This can be optimised by leveraging the collective intelligence enabled by a post-Turing scenario. So we need to introduce an "open hardware" approach [1], where all specifications and documentation are available to experts.

Smart software applications could be also useful in supporting us in decreasing our environmental impact, reaching our main goals and satisfying our significant values.

In the "remote working" area we need to start a new way of thinking that questions the exploitation of knowledge workers: they are the best candidates to become independent workers instead of "employees" of some intermediate obscure job brokers. On the social side of post-Turing ICT the long list of issues in front of us will require a new interdisciplinary approach that will enable the collaboration of many disciplines like: computing and networking, sociology, psychology, anthropology, and philosophy. It is the first time in our history that we have this opportunity at global scale; let us stay humans.

\section{References}

1. Arduino, http: / / www . arduino. cc (accessed March 2012)

2. Baliga, J., Ayre, R.W.A., Hinton, K., Tucker, R.S.: Green Cloud Computing: Balancing Energy in Processing, Storage, and Transport. Proceedings of the IEEE 99(1), 149-167 (2011), Issue Date: January

3. BBC: Finland makes broadband a 'legal right', BBC news (July 1, 2010)

4. Cisco: Cisco Visual Networking Index: Global Mobile Data Traffic Forecast Update (2011-2016),

http: / /www.cisco.com/en/US/solutions/collateral/ns341/ns525/ ns537/ns705/ns827/white_paper_c11-520862.html

(accessed February 2012) 
5. Codrington, G.: Freelancers, eLancers and Cloud workers, TomorrowToday (July 6, 2010)

6. Internetworldstats: Internet Usage Statistics, The Internet Big Picture, World Internet Users and Population Stats (2012),

http: / /www. internetworldstats.com/stats.htm (accessed February 2012)

7. ISC: Internet Software Consortium, Domain Survey last update (2012),

http: / / www. isc.org/solutions / surveym (accessed February 2012)

8. ISPRA (Istituto Superiore per la Protezione e la Ricerca Ambientale): Rapporto Rifiuti, Rome (2007), http: / / www . ispra . gov . it (accessed June 2011)

9. Issenberg S.: Obama's White Whale. How the campaign's top-secret project Narwhal could change this race, and many to come (February 15, 2012), slate.com

10. Kock, N.: Encyclopedia of E-collaboration. Information Science Reference (2007)

11. Koomey, J.G.: Estimating total power consumption by servers in the US and the world. Lawrence Berkeley National Laboratory, Stanford University, Stanford CA (2007)

12. Lessig, L.: Free Culture, The Nature and Future of Creativity. Penguin Books (2005)

13. Licklider, J.C.R.: Man-Computer Symbiosis. IRE Transactions on Human Factors in Electronics HFE-1, 4-11 (1960)

14. Moore, G.E.: Cramming more components onto integrated circuits. Electronics Magazine (April 19, 1965)

15. OECD (Organization for Economic Cooperation and Development): Information Technology Outlook, OECD, Paris (2010), http: / /www . oecd. org (accessed June 2011)

16. Ostrom, E., Hess, C. (eds.): Understanding Knowledge as a Commons: From Theory to Practice. The MIT Press, Cambridge (2006)

17. Patrignani, N., Laaksoharju, M., Kavathatzopoulos, I.: Challenging the Pursuit of Moore's Law: ICT Sustainability in the Cloud Computing Era. In: Whitehouse, D., Hilty, L., Patrignani, N., VanLieshout, M. (eds.) Notizie di Politeia - Rivista di Etica e Scelte Pubbliche, Anno XXVII, Milano, Italy, vol. (104) (2011)

18. RSF: Enemies of the Internet, http: / /www.rsf . org (released March 2011)

19. Schmitz, O.J., Graedel, T.E.: The Consumption Conundrum: Driving the Destruction Abroad, e360.yale.edu (April 2010)

20. Soesterberg: Trans-Atlantic Network for Clean Production Meeting. Soesterberg, The Netherlands (May 1999), http: / / icspac.net/anpedwg/publications . aspx (accessed June 2011)

21. SVTC (Silicon Valley Toxics Coalition) (2007), http://svtc.org (accessed June 2011)

22. Turing, A.: On computable numbers, with an application to the Entscheidungsproblem. In: Proceedings of the London Mathematical Society, Ser. 2, vol. 42 (1937)

23. Vaidhyanathan, S.: The Googlization of Everything: And Why We Should Worry. University of California Press (2011)

24. Vazquez-Figueroa, A. Coltan. Ediciones B (2010)

25. W3C: Linking Open Data, W3C SWEO Community Project (2012), http: / /www.w3 .org/wiki/SweoIG/TaskForces/CommunityProjects / LinkingOpenData (accessed February 14, 2012) 